\title{
Novel Approaches for Efficient Delivery of Tyrosine Kinase Inhibitors
}

\author{
Zahra moradpour ${ }^{1}$, Leila Barghi ${ }^{2}$ \\ ${ }^{1}$ Department of Pharmaceutical biotechnology and ${ }^{2}$ Department of Pharmaceutics, School of Pharmacy, Urmia University \\ of medical sciences, Urmia, Iran.
}

Received, September 15, 2018; Revised October 25, 2018; Accepted, January 7, 2019; Published, January 9, 2018.

\begin{abstract}
Epidermal growth factor receptors (EGFRs) have potential to be considered as therapeutic target for cancer treatment especially in cancer patients with overexpression of EGFR. Cetuximab as a first monoclonal antibody and Imatinib as the first small molecule tyrosine kinase inhibitor (SMTKI) were approved by FDA in 1998 and 2001. About 28 SMTKIs have been approved until 2015 and a large number of compound with kinase inhibitory activity are at the different phases of clinical trials. Although Kinase inhibitors target specific intracellular pathways, their tissue or cellular distribution are not specific. So treatment with these drugs causes serious dose dependent side effects. Targeted delivery of kinase inhibitors via dendrimers, polymeric nanoparticles, magnetic nanoparticles and lipid based delivery systems such as liposomes, solid lipid nanoparticles (SLN) and nanostructured lipid carriers (NLC) can lead to reduction of side effects and improving therapeutic efficacy of the drugs in the target organs. Furthermore formulation of these drugs is challenged by their physicochemical properties such as solubility and dissolution rate. The main approaches in order to increase dissolution rate, are particle size reduction, self-emulsification, cyclodextrin complexation, crystal modification and amorphous solid dispersion. Synergistic therapeutic effect, decreased side effects and drug resistant, reduced cost and increased patient compliance are the advantages associated with using combination therapy especially in the treatment of cancer. Combination of TKIs with chemotherapeutic agents or biopharmaceuticals such as monoclonal antibodies and oligonucleotides and also combination of two TKIs within one formulation is possible by new targeting delivery systems. This article reviews the recent advances in the design and development of delivery systems for TKIs.
\end{abstract}

\section{INTRODUCTION}

Epidermal growth factor receptors (EGFRs) are cell membrane bound proteins which are belonging to human epidermal receptors (HERs) family. EGFRs are over expressed in various types of solid tumors which is responsible for pathogenesis, proliferation, invasion, angiogenesis and metastasis (1). These receptors are consisting of three regions: an extracellular ligand binding site; an intracellular domain with tyrosine kinase activity and regulatory functions; and a region that binds the receptor to the cell membrane (2-4). Inhibition of tyrosine kinase leads to apoptosis promotion, inhibition of angiogenesis and finally preventing excessive cell proliferation (5-7). Therapeutic response of cancer patients with overexpression EGFR to both chemotherapy and radiation therapy is poor (1). Therefore these receptors have potential to be considered as therapeutic targets (7). Concept of epidermal growth factor receptors inhibition was defined by introducing of Cetuximab as a monoclonal antibody in 1998 (8). It selectively binds to EGFR and competitively inhibits binding of epidermal growth factor to its receptor (9-10). Then Imatinib as the first small molecule tyrosine kinase inhibitor (SMTKI) was approved by FDA for treatment of chronic myeloid leukemia in 2001 (11). About 28 SMTKIs have been approved until 2015 and a large number of compound with kinase inhibitory activity are at the different phases of clinical trials (12). Although the vital role of SMTKIs is in the field of oncology, other indications of these compounds investigated and finally led to approval of Tofacitinib for rheumatoid arthritis and Nintedanib for pulmonary fibrosis (13-14). Even though kinase inhibitors are belonged to the type of drugs that target specific intracellular pathways, their tissue or cellular distribution are not specific.

Corresponding Author: Leila Barghi, Pharm.D. PhD. Department of Pharmaceutics, School of Pharmacy, Urmia University of Medical Sciences, Urmia, Iran; E mail address: Leila.barghi@gmail.com 
Thus treatment with these drugs causes serious dose dependent side effects. Targeted delivery of kinase inhibitors can lead to decrease side effects and increase the therapeutic efficacy of the drug in the target organ (15). Also improvement in the treatment of diseases can be achieved by pharmacokinetics alteration via increasing the circulation time of the drug. For instance the treatment of glioblastoma or other central nervous system disorders are limited by biological barriers such as blood brain barrier hence specific targeting may improve transport of kinase inhibitors over this barrier (16-17). A summary of investigated delivery systems for various TKIs are demonstrated in table 1. Another approach to improve therapeutic efficacy, reduce drug resistant and also decrease adverse effects in the field of oncology is combination therapy. Combination of TKIs with chemotherapeutic agents or biopharmaceuticals such as monoclonal antibodies and oligonucleotides and also combination of two TKIs within one formulation is possible by new targeting delivery systems (18-20). In this paper we review novel delivery systems which can be used as efficient delivery of TKIs.

\section{NOVEL TARGETING DELIVERY OF TKIS}

Targeting delivery of tyrosine kinase inhibitors are possible via various approaches such as dendrimers, polymeric nanoparticles, magnetic nanoparticles and lipid based delivery systems such as liposomes, solid lipid nanoparticles (SLN) and nanostructured lipid carriers (NLC). Methods of preparation, utilized In vivo tests and outcomes of various delivery systems for TKIs are shown in table 2 .

\section{Dendrimers}

Dendrimers are branched mono-disperse spherical polymers. Dendrimers molecules consist of a group of atoms as the core and the branches of other atoms added to the core via the variety of chemical reactions. The core molecule reacts with reactive monomers via step by step controlled synthesis and different generation of dendrimers is produced in each step. Their suitable structures make them as suitable carriers in drug and gen delivery (21-23). Prolonged residence time of the drug in the blood circulatory system is the direct result of dendrimers pegylation by altering solubility, biodistribution and pharmacokinetics (24). Therefore pegylated 5ith generation (G5) Poly (propylene imine) dendrimers were synthesized as delivery systems for Imatinib. The aqueous solubility of Iimatinib was increased in these dendrimers based delivery systems (25). Cationic polyamidoamine (PAMAM) dendrimers have an ethylenediamine core and branches with terminal amino (-NH2) groups (26). Dolman et al developed a Sunitinib-dendrimer conjugate via the platinum linker for delivery of Sunatinib into the proximal tubular cells of kidney. They conjugated Sunitinib to the terminal amines of PAMAM-G3. They concluded that in vivo accumulation of this novel compound make it suitable as efficient dendrimer therapeutics for the treatment of renal disease (27).

\section{Polymeric nanoparticles}

The polymeric nanoparticles are prepared from biocompatible and biodegradable polymers with size ranged between 10 to $1000 \mathrm{~nm}$. Drugs can be dissolved, entrapped, encapsulated or attached to a nanoparticles matrix. Nanospheres and nanocapsules are two types of nanoparticles which can be obtained depending on their preparation method (28). The most extensive pharmaceutical researches on the topic of nanoparticles have been focused in the area of oncology because nanocarriers can concentrate preferentially in tumor masses, inflammatory sites, and infectious sites by enhanced permeability and retention (EPR) effect on the vasculature.

Table1. A summary of investigated delivery systems for various TKIs

\begin{tabular}{lll}
\hline Drug & Delivery systems & References \\
\hline Erlotinib & $\begin{array}{l}\text { Polymeric nanoparticles, Galactosylated liposomes, Solid lipid nanoparticles, } \\
\text { cyclodextrin nanosponge, Solid self-emulsifying systems }\end{array}$ & $(33,51,57,64,79)$ \\
Imatinib & $\begin{array}{l}\text { Dendrimer based delivery systems, Polymeric nanoparticles, Nanostructured } \\
\text { lipid carriers }\end{array}$ & $(25,39,58)$ \\
Sunitinib & Dendrimer based delivery systems & $(27)$ \\
Apatinib & Pegylated polymeric nanoparticles, Pegylated cRGD liposomes & $(38,50)$ \\
Nilotinib & Solid dispersion & $(73)$ \\
\hline
\end{tabular}


This effect is based on the fact that pathological vasculature, unlike vasculature of normal healthy tissues, is leaky. It means that large molecules and even small particles can penetrate and accumulate in the interstitial tumor space via this effect. Such accumulation is additionally facilitated by the virtual lack of a lymphatic system which is responsible for the drainage of macromolecules from normal tissues and increased production of a number of permeability mediators in many tumors. It has been reported that the effective pore size in the endothelial lining of the blood vessels in most peripheral human tumors ranges from $200 \mathrm{~nm}$ to $600 \mathrm{~nm}$ in diameter. Depending on the cutoff size of the leaky vasculature, passive targeting of nanoparticles to tumors is possible (29-32). PLGA nanoparticles containing Erlotinib hydrochloride were produced by Marslin et al. They found that these nanoparticles demonstrated less sub-acute toxicity than free drug in rats (33). In another study which was conducted by Barghi et al. Erlotinib loaded nanoparticles were prepared following synthesis of poly caprolactoneethylene glycol- caprolactone (PCEC). Triblock PCEC copolymers were synthesized by ring opening polymerization method and then Erlotinib loaded PCEC nanoparticles were prepared via solvent displacement method. They concluded that the prepared PCEC nanoparticles might have the potential to be considered as delivery system for Erlotinib (34-36). Human serum albumin (HSA)conjugated polyethylene glycol containing Apatinib for treatment of ocular diseases, including corneal neovascularization via suppressing angiogenesis was prepared by Lee et al. They demonstrated subconjunctival injection of these nanoparticles significantly reduced corneal neovascularization, whereas the injection of free Apatinib solution did not show this effect. The most limitation of free drug subconjunctival injection is the rapid clearance of these drugs from ocular tissue. Therefore sustained release of Apatinib from HSA-PEG nanoparticles can increase its therapeutic efficacy (37-38). Furthermore Imatinib mesylate-loaded polybutylcyanoacrylate nanoparticles were prepared and evaluated. Their high encapsulation efficiency $(86 \%)$ and appropriate cytotoxicity profile make them as valuable system for delivery of Imatinib to leukemia cell line K562 (39).

\section{Magnetic nanoparticles}

Delivery of drugs to the target organ is possible via their incorporating in Magnetic nanoparticles. By using an external magnetic field, drugs are concentrated in target sites (40). In the study which was conducted by $\mathrm{Xu}$ et al. Erlotinib loaded multifunctional magnetic nanoparticles were prepared. Firstly multifunctional, carbon-coated, iron nanoparticles $(\mathrm{C} / \mathrm{Fe} \mathrm{MNPs})$ were synthesized using the radio-frequency chemical vapor deposition method. Then erlotinib was incorporated onto the surface of $\mathrm{C} / \mathrm{Fe}$ MNPs through the relatively simple noncovalent - stacking process. These nanoparticles show strong magnetic properties due to their atomic iron-core structures. The carbon shells are very stable and easy to bio-functionalize, making such nanoparticles very well dispersible in aqueous solutions, and thereby especially suitable for use in biological applications. (41).

\section{Liposomes}

Liposomes are artificial phospholipid vesicles without any toxic or antigenic reactions. Size of these vesicles which are biologically inert and completely biocompatible is in the range of 50 to 100 $\mathrm{nm}$. Water-soluble drugs can be loaded into their inner aqueous compartment and water insoluble drugs can be incorporated into the hydrophobic compartment of their phospholipid bilayer (32). Liposomes can be passively accumulated in tumors through EPR effect (42). Nevertheless they eliminated from the body via rapid clearance by the reticuloendothelial system. Thus pegylated liposomes have been used in order to overcome this problem (43). Besides passive targeting mechanism, liposomes exhibit active targeting by adding various specific ligands such as antibodies and integrin ligands (44). Integrin $\alpha v \beta 3$ is overexpressed in most tumors which are responsible for tumor angiogenesis, growth, and metastasis. One of the integrin ligands which recognized by Integrin $\alpha v \beta 3$, is a tripeptide consisting of arginine-glycineaspartic acid (RGD). Thus by modification of liposomes with RGD, active targeting of drugs to tumors is possible (45). Although Linear RGD peptides are active against several integrins but they don't show suitable selectivity profile. Cyclization of RGD peptides increases their binding affinity and selectivity (46-47). Therefore by synthesis of multiple cyclic RGD peptides, such as c(RGDfK), $\mathrm{c}(\mathrm{RGDyK})$, RGD4C and RGD10, affinity and selectivity of these ligands was improved (48-49). Pegylated Apatinib loaded cRGD liposomes were developed by Song et al. recently in order to passive and active targeting with long circulation time in the 
body. They concluded that these modified Apatinib liposomes could be shown high efficacy in treatment of colon cancer (50). In another study galactosylated Erlotinib liposomes were developed for treatment of lung cancer by solvent evaporation method. Results demonstrated improvement of drug targeting and increasing relative bioavailability of Erlotinib from galactosylated liposomes were possible (51).

\section{Solid lipid nanoparticles (SLN) and nanostructured lipid carriers (NLC)}

SLNs are drug-delivery systems containing solid lipids which are dispersed in an aqueous medium. Fatty acids, steroids, waxes, monoglycerides, diglycerides and triglycerides are used as solid lipid in their structure (52). SLNs may be used for incorporating both hydrophilic and hydrophobic drugs (53). NLCs are composed of both solid and liquid lipids. Stability and loading capacity of drugs which is delivered by NLCs in comparison to drugs incorporated to SLNs is improved (54-56). Lipid based drug delivery systems including SLNs and NLCs have been used extensively for cancer treatment in recent years. For example in a study, Erlotinib loaded solid lipid nanoparticles were prepared and then spray dried by using mannitol as carrier in order to prepare dry powder inhaler (DPI). Therefore microparticles containing erlotinib SLN with appropriate flowability and aerodynamic properties for pulmonary delivery of erlotinib were prepared (57). Imatinib loaded NLCs was prepared via "hot homogenization followed by sonication using labrafi as liquid lipid and precirol as solid lipid by Gupta et al. Their In vitro and pharmacokinetic evaluation revealed that this lipid-based formulation might have the potential to be considered as efficient delivery system for Erlotinib (58).

\section{SOLUBILITY MODIFICATION OF TKIS}

Most of the drugs which belongs to TKIs are poor soluble; some of them with high permeability and others with low permeability. Hence, TKIs belong to class II or IV Biopharmaceutical Classification System (BCS). Class II and class IV (BCS) characterized by low solubility, high permeability and low solubility, low permeability respectively. Bioavailability of class II drugs are limited by dissolution rate but bioavailability of class IV drugs are dependent on both dissolution and permeability (59-60). Therefore, the most important strategy to improve bioavailability of the class II and IV is their dissolution enhancement. The main approaches in order to increase dissolution rate, are particle size reduction, self-emulsification, cyclodextrin complexation, crystal modification and amorphous solid dispersion (61-64).

\section{Nanocrystal formation}

The solubility of nanocrystals are appropriate due to their very high surface area and they can be incorporated into oral products by numerous methods of solidification such as spray drying(65), lyophilization (66), and electro-spraying (67). Physical and chemical stability of liquid nanosuspensions were improved by solidification methods. Erlotinib nanocrystals were produced for incorporating in solid dosage forms by Thakkar et al. Firstly they prepared erlotinib nanosuspension via nanoprecipitation technique followed by probe sonication. Methanol, ethanol, acetone, dichloromethane and ethyl acetate as solvent and Pluronic ${ }^{\circledR}$ F-127, Pluronic ${ }^{\circledR}$ F-68, SLS, and PVP K30 as stabilizer were used in this study. Then nanosuspensions were solidified via both lyophilization and electro-spraying methods. Lyophilized powder had superior physicochemical properties in comparison to electrosprayed powders (68).

\section{Solid dispersions}

Another formulation development approach for solubility enhancement involves formation of amorphous form of drugs (69). Higher Gibbs free energy of amorphous drugs than crystalline drugs let them to have higher solubility (70). However amorphous materials are unstable (71). Therefore amorphous form of drugs is incorporated into polymer matrixes due to formation of solid dispersion (72). Nilotinib spray dried solid dispersion was developed by Herbrink et al (73). Nilotinib Hydrochloride is poorly soluble and also its permeability is low because of P-gp transporters which efflux Nilotinib out of cell; hence it belongs to (BCS) class IV (74). In this study various polymers such as Kollidon, Lutrol and Soluplus with different drug:polymer ratios were used. Among them, coblock polymer Soluplus with 1:7 (Nilotinib: Soluplus) ratio exhibited improved solubility which resulted in high bioavailability (73).

\section{Solid self-emulsifying drug delivery systems}

One of the approaches in order to increase dissolution rate, is developing self-Emulsifying drug delivery systems (SEDDS) (75). These systems are 
containing oils, surfactants, co-surfactants and cosolvent which can be used in order to deliver lipophilic drugs. They spontaneously form oil-in water emulsions while exposed to aqueous medium (76). The most important problem related to the conventional SEDDS is their storage instability. Solidification of these delivery systems is the beneficial procedure to overcome this problem (7778). In a study was performed by Truong et al. solid SEDDS formulations of Erlotinib were prepared by spray drying method (79). Erlotinib belongs to the (BCS) class II with low solubility and high permeability. Therefore rate limiting step for absorption of Erlotinib from oral solid dosage form is the dissolution phase (80-81). In a study was performed by Truong et al. the liquid SEDDS formulations were initially prepared by dissolving Erlotinib in mixtures of the various oil, surfactant, and co-surfactant at room temperature. Then, spray drying procedure were used in order to prepare solid SEDDS formulations. Dextran 40 and colloidal silica (Aerosil@ 200) were chosen as the carriers for construction of solid SEDDS. Their results demonstrated that Erlotinib was in the amorphous state in solid SEDDS and exhibited faster dissolution rate than pure drug. Their pharmacokinetic studies in rats indicated that bioavailability of Erlotinib in these formulations was improved in comparison to pure drug (79).

\section{Cyclodextrin complexation}

Cyclodextrins are cyclic oligosaccharides containing six, seven, eight or nine glucose units. Cyclodextrins are water soluble because of their hydrophilic surface and they can form inclusion complexes with a various types of hydrophobic molecules due to their hydrophobic interior $(63,82-83)$. The cyclodextrin-based nanosponges are crosslinked polymeric systems composed of $\beta$ - cyclodextrins with a high capacity to interact with small molecules in its matrix and a suitable crosslinker such as carbonyldiimidazole, pyromellitic dianhydride and diphenyl carbonate. Cyclodextrin-based nanosponges can form complexes with different types of lipophilic or hydrophilic molecules (84-85). For instance Erlotinib $\beta$ cyclodextrin nanosponges were prepared using carbonyldiimidazole as crosslinker in order to enhance solubility and oral bioavailability of Erlotinib. Therefore solubility and oral bioavailability improvement of Erlotinib in these formulations may result in its reduction in dose and dose related side-effects (64).

\section{DELIVERY SYSTEMS FOR COMBINATION THERAPY OF TKIS}

Synergistic therapeutic effect, reduced side effects and drug resistance, reduced cost and increased patient compliance are the advantages associated with using combination therapy especially in the treatment of cancer (86-87). A clinical trial was performed by Lee et al. in order to evaluate efficacy of Afatinib and Nimotuzumab combination. Combination therapy showed therapeutic benefit in Non-small cell lung cancer (NSCLC) patients with acquired resistance to Gefitinib or Erlotinib (88). Effectiveness of Erlotinib and Bevacizumab; an antivascular endothelial growth factor (VEGF) antibody combination and also combination of Geftinib and Bevacizumab evaluated and the results showed promising effect for treatment of lung cancers patients with EGFR mutations (89-90). Moreover Triplet therapy with Afatinib, Cetuximab, and Bevacizumab demonstrated appropriate outcomes in the treatment of lung cancers patients with EGFR mutations (91). Lapatinib could sensitize human epidermal growth factor receptor-2 (HER-2) positive gastric cancer to Paclitaxel and exhibit synergetic effect with Paclitaxel in clinical trial (92). A novel micellar system by using poly ethylene glycol and poly lactic acid (PEG- PLA) diblock copolymers containing Lapatinib and Paclitaxel were prepared by Wei et al. They concluded that Lapatinib could extremely increase antineoplastic effect of paclitaxel via co-delivery of Lapatinib and Paclitaxel by this novel micellar system (93). For codelivery of Lapatinib and Paclitaxel, additional novel system was described by $\mathrm{Hu}$ et al. They incorporated Paclitaxel nanoparticles and Lapatinib microparticles into a thermosensitive hydrogel for peritumoral injection (94). Furthermore Co-delivery of Lapatinib and Paclitaxel through liposomal formulation was described by Ravar et al (95). Folate receptor targeted $\mathrm{pH}$-sensitive pegylated liposomes containing both Imatinib and Doxorubicin which can be delivered two drugs in tumor acidic environment is a novel approach to improve chemotherapeutic efficacy against MDR tumors (96). Furthermore, nanostructured lipid carriers (NLCs) containing Curcumin and Imatinibwere prepared and conjugated to high-density lipoprotein (HDL) to target scavenger receptor type B-1 which is expressed by lymphoma cells. 
Table2. An overview of preparation methods, utilized In vivo tests and outcomes of various delivery systems for TKIs

\begin{tabular}{|c|c|c|c|c|c|}
\hline Delivery system & Drug & Method & In vivo tests & Outcome & Reference \\
\hline $\begin{array}{l}\text { Dendrimer based delivery } \\
\text { systems }\end{array}$ & Imatinib & Dialysis & - & $\begin{array}{l}\text { Aqueous } \\
\text { solubility } \\
\text { enhancement }\end{array}$ & $(25)$ \\
\hline $\begin{array}{l}\text { Dendrimer based delivery } \\
\text { systems }\end{array}$ & Sunitinib & Conjugation & $\begin{array}{l}\text { renal } \\
\text { accumulation } \\
\text { assay }\end{array}$ & $\begin{array}{l}\text { In vitro } \\
\text { internalization } \\
\text { and in vivo } \\
\text { kidney } \\
\text { accumulation }\end{array}$ & (27) \\
\hline PLGA nanoparticles & Erlotinib & $\begin{array}{l}\text { Sonication- } \\
\text { solvent } \\
\text { evaporation }\end{array}$ & toxicity test & $\begin{array}{l}\text { Less subacute } \\
\text { toxicity }\end{array}$ & (33) \\
\hline $\begin{array}{l}\text { Pegylated HAS polymeric } \\
\text { nanoparticles }\end{array}$ & Apatinib & $\begin{array}{l}\text { Thin film } \\
\text { rehydration }\end{array}$ & $\begin{array}{l}\text { corneal } \\
\text { distribution }\end{array}$ & $\begin{array}{l}\text { Decreasing } \\
\text { clearance of } \\
\text { drug from } \\
\text { ocular tissue }\end{array}$ & (38) \\
\hline $\begin{array}{l}\text { Polybutylcyanoacrylate } \\
\text { nanoparticles }\end{array}$ & Imatinib & $\begin{array}{l}\text { Miniemulsion } \\
\text { polymerization }\end{array}$ & - & $\begin{array}{l}\text { High } \\
\text { encapsulation } \\
\text { efficiency and } \\
\text { appropriate } \\
\text { cytotoxicity } \\
\text { profile }\end{array}$ & (39) \\
\hline $\begin{array}{l}\text { Pegylated cRGD } \\
\text { liposomes }\end{array}$ & Apatinib & $\begin{array}{l}\text { Thin-film } \\
\text { hydration }\end{array}$ & $\begin{array}{l}\text { antitumor efficacy } \\
\text { test }\end{array}$ & $\begin{array}{l}\text { High cellular } \\
\text { uptake, } \\
\text { improvement in } \\
\text { biodistribution } \\
\text { and tumor } \\
\text { selectivity }\end{array}$ & (50) \\
\hline Galactosylated liposomes & Erlotinib & $\begin{array}{l}\text { Solvent } \\
\text { evaporation } \\
\text { method }\end{array}$ & $\begin{array}{l}\text { Biodistribution } \\
\text { studies }\end{array}$ & $\begin{array}{l}\text { Improvement of } \\
\text { body } \\
\text { distribution and } \\
\text { relative } \\
\text { bioavailability } \\
\text { enhancement }\end{array}$ & (51) \\
\hline $\begin{array}{l}\text { Nanostructured lipid } \\
\text { carriers }\end{array}$ & Imatinib & $\begin{array}{l}\text { Hot } \\
\text { homogenization }\end{array}$ & $\begin{array}{l}\text { pharmacokinetic } \\
\text { studies }\end{array}$ & $\begin{array}{l}\text { Bioavailability } \\
\text { enhancement }\end{array}$ & (58) \\
\hline Erlotinib Nanocrystals & Erlotinib & $\begin{array}{l}\text { Nanoprecipitation } \\
\text { followed by } \\
\text { Lyophilization or } \\
\text { electrospraying }\end{array}$ & - & $\begin{array}{l}\text { Solubility } \\
\text { enhancement }\end{array}$ & (68) \\
\hline Solid dispersion & Nilotinib & Spray drying & - & $\begin{array}{l}\text { Solubility } \\
\text { enhancement }\end{array}$ & (73) \\
\hline $\begin{array}{l}\text { Solid self-emulsifying } \\
\text { systems }\end{array}$ & Erlotinib & Spray drying & $\begin{array}{l}\text { pharmacokinetic } \\
\text { study }\end{array}$ & $\begin{array}{l}\text { Solubility and } \\
\text { bioavailability } \\
\text { enhancement }\end{array}$ & (79) \\
\hline $\begin{array}{l}\text { Erlotinib cyclodextrin } \\
\text { nanosponge }\end{array}$ & Erlotinib & $\begin{array}{l}\text { Complexation and } \\
\text { freeze drying }\end{array}$ & $\begin{array}{l}\text { pharmacokinetic } \\
\text { study }\end{array}$ & $\begin{array}{l}\text { Solubility and } \\
\text { oral } \\
\text { bioavailability } \\
\text { enhancement }\end{array}$ & (64) \\
\hline
\end{tabular}

Their findings suggested that NLCs delivery system containing curcumin and Imatinib can be more beneficial than Imatinib alone in the treatment of B cell lymphoma (97). Using TKIs in combination with Short interfering RNA (siRNA) is additional strategy for efficient treatment of cancers. Various 
siRNA molecules including anti-drug resistance siRNA, EGFR siRNA and VEGF siRNA can be used with TKIS simultaneously to overcome drug resistant, prevent angiogenesis and improve therapeutic efficacy of TKIs (18, 98-100). For instance the porous gelatin triblock nanoparticles containing Geftinib and Cetuximab- siRNA conjugate was synthesized. Initially gelatin nanoparticles were prepared via two steps desolvation process. Geftinib was incorporated to nanoparticles prior the second desolvation step. The carboxyl groups on the surface of the Geftinib loading nanoparticles activated and reacted with Cetuximab in order to preparation of Cetuximab conjugated nanoparticles and finally conjugation of Cetuximab to siRNA was performed (98). The nucleic acid based drugs such as siRNA have hydrophilic structure and are negatively charged. Therefore delivery of these drugs inside the cells is a complicated process. Instability of siRNA due to enzymatic degradation is additional drawback (101). It has demonstrated that porous gelatin triblock nanoparticles containing Geftinib and CetuximabsiRNA conjugate can efficiently deliver siRNA to cytoplasm of KRAS mutant H23 non-small cell lung cancer (NSCLC) cells (98).

\section{CONCLUSION}

Drugs which belongs to TKIs are poor soluble; some of them with high permeability and others with low permeability. Hence, TKIs belong to class II or IV Biopharmaceutical Classification System (BCS). Formulations of these drugs are considered challenging because of their physicochemical properties such as solubility, dissolution rate and permeability. Therefore, various approaches are being investigated to design and develop novel and efficient delivery systems for TKIs in recent years. The difficulties confronted by the conventional formulations such as dose dependent side effects, variable bioavailability and non-specific tissue distribution have been addressed by utilizing novel strategies particularly nanostructured systems. Drug resistance caused by efflux mechanism, have been explored to minimize via combination of TKIs with other drugs using Co-delivery of TKIs with chemotherapeutic agents or biopharmaceuticals such as monoclonal antibodies and oligonucleotides. In this regard, combination of two TKIs is also found favorable as included in new targeting delivery systems like NLCs, pegylated liposomes and nanoparticles. Although considerable amount of delivery systems for TKIs are under investigations, but further in vivo studies are essential to confirm therapeutic benefits of these formulations compared to free drugs.

\section{CONFLICT OF INTEREST}

The authors report no conflict of interest.

\section{ABBREVIATIONS}

EGFRs: Epidermal growth factor receptors; HERs: Human epidermal receptors; SMTKI: Small molecule tyrosine kinase inhibitor; TKI: Tyrosine kinase inhibitor; EPR: Enhanced permeability and retention; SLN: Solid lipid nanoparticle; NLC: Nanostructured lipid carrier; PAMAM: Polyamidoamine; PCEC: Poly caprolactoneethylene glycol- caprolactone; HSA: Human serum albumin; RGD: Arginine-glycine-aspartic acid; BCS: Biopharmaceutical Classification System; SEDDS: self-Emulsifying drug delivery systems

\section{RERERENCES}

1. Pao W, Miller VA. Epidermal growth factor receptor mutations, small-molecule kinase inhibitors, and non-small-cell lung cancer: Current knowledge and future directions. Journal of Clinical Oncology. 2005;23(11):2556-68.

2. Danielle M G. Molecular targets in cancer therapy. Seminars in Oncology Nursing. 2003;19(3):193-205.

3. Janine S. Erlotinib: Small-molecule targeted therapy in the treatmentof non-small-cell lung cancer. Clinical Therapeutics. 2005;27(10):1513-34.

4. Ullrich A, Schlessinger J. Signal transduction by receptors with tyrosine kinase activity. Cell. 1990;61(2):203-12. DOI: 0092-8674(90)90801-K

5. Clay D, Lipman YM, Bonk ME. Erlotinib (Tarceva $\left.{ }^{\circledR}\right)$ : A brief overview: The authors review erlotinib (Tarceva $\left.{ }^{\circledR}\right)$ for the treatment of non-smallcell lung cancer. P and T. 2005;30(10):561-2+71$72+602$.

6. Makrilia N, Lappa T, Xyla V, Nikolaidis I, Syrigos $\mathrm{K}$. The role of angiogenesis in solid tumours: An overview. European Journal of Internal Medicine. 2009;20(7):663-71.

7. Smith J. Erlotinib: small-molecule targeted therapy in the treatment of non-small-cell lung cancer. Clin Ther. 2005 t;27(10):1513-34.

8. Kinch MS. An analysis of FDA-approved drugs for oncology. Drug discovery today. 2014;19(12):18315. DOI: 10.1016/j.drudis.2014.08.007 
9. Dervisis N, Klahn S. Therapeutic Innovations: Tyrosine Kinase Inhibitors in Cancer. Veterinary sciences. 2016;3(1). DOI: 10.3390/vetsci3010004

10. Ferrara N, Hillan KJ, Novotny W. Bevacizumab (Avastin), a humanized anti-VEGF monoclonal antibody for cancer therapy. Biochemical and biophysical research communications. 2005;333(2):328-35.

DOI:

10.1016/j.bbrc.2005.05.132

11. O'Brien Z, Fallah Moghaddam M. Small molecule kinase inhibitors approved by the FDA from 2000 to 2011: a systematic review of preclinical ADME data. Expert opinion on drug metabolism \& toxicology. 2013;9(12):1597-612.

DOI: 10.1517/17425255.2013.834046

12. Rask-Andersen M, Zhang J, Fabbro D, Schiöth HB. Advances in kinase targeting: current clinical use and clinical trials. Trends in Pharmacological Sciences.2007; 5(11):604-20. DOI: 10.1016/j.tips.2014.09.007

13. Gomez-Puerta JA, Mocsai A. Tyrosine kinase inhibitors for the treatment of rheumatoid arthritis. Current topics in medicinal chemistry. 2013;13(6):760-73.

14. Huang Z, Li H, Zhang Q, Lu F, Hong M, Zhang Z, et al. Discovery of Indolinone-Based Multikinase Inhibitors as Potential Therapeutics for Idiopathic Pulmonary Fibrosis. ACS medicinal chemistry letters. 2017;8(11):1142-7. DOI: 10.1021/acsmedchemlett.7b00164

15. Isil A, Raymond S, Robbert Jan K. Targeted Delivery of Kinase Inhibitors: A Nanomedicine Approach for Improved Selectivity in Cancer. Current Signal Transduction Therapy. 2011;6(2):267-78.

16. Engelman JA, Settleman J. Acquired resistance to tyrosine kinase inhibitors during cancer therapy. Current opinion in genetics \& development. 2008;18(1):73-9. DOI: 10.1016/j.gde.2008.01.004

17. van Beuge MM, Poelstra K, Prakash J. Specific delivery of kinase inhibitors in nonmalignant and malignant diseases. Expert opinion on drug delivery. 2012;9(1):59-70.

DOI:10.1517/17425247.2012.638625

18. Wu L, Leng D, Cun D, Foged C, Yang M. Advances in combination therapy of lung cancer: Rationales, delivery technologies and dosage regimens. J Control Release. 2017 Aug 28;260:78-91. DOI: 10.1016/j.jconrel.2017.05.023

19. Meng J, Dai B, Fang B, Bekele BN, Bornmann WG, Sun $\mathrm{D}$, et al. Combination treatment with MEK and AKT inhibitors is more effective than each drug alone in human non-small cell lung cancer in vitro and in vivo. PloS one. 2010;5(11):e14124. DOI: 10.1371/journal.pone.0014124

20. Steiner P, Joynes C, Bassi R, Wang S, Tonra JR, Hadari YR, et al. Tumor growth inhibition with cetuximab and chemotherapy in non-small cell lung cancer xenografts expressing wild-type and mutated epidermal growth factor receptor. Clinical cancer research : an official journal of the American Association for Cancer Research. 2007;13(5):154051. DOI: 10.1158/1078-0432.ccr-06-1887

21. Abbasi E, Aval SF, Akbarzadeh A, Milani M, Nasrabadi HT, Joo SW, et al. Dendrimers: synthesis, applications, and properties. Nanoscale Research Letters. 2014;9(1):247. DOI: 10.1186/1556-276X-9247

22. Nanjwade BK, Bechra HM, Derkar GK, Manvi FV, Nanjwade VK. Dendrimers: emerging polymers for drug-delivery systems. European journal of pharmaceutical sciences : official journal of the European Federation for Pharmaceutical Sciences. 2009;38(3):185-96. DOI: 10.1016/j.ejps.2009.07.008

23. D'Emanuele A, Attwood D. Dendrimer-drug interactions. Advanced drug delivery reviews. 2005 ;57(15):2147-62. DOI: 10.1016/j.addr.2005.09.012

24. Esfand R, Tomalia DA. Poly(amidoamine) (PAMAM) dendrimers: from biomimicry to drug delivery and biomedical applications. Drug discovery today. 2001;6(8):427-36.

25. Karthikeyan R. PEGylated Nanoarchitechture Mediated Solubility Enhancement of TyrosineKinase Inhibitor. 2015;(2):1-4.

26. Akhtar S, Al-Zaid B, El-Hashim AZ, Chandrasekhar B, Attur S, Yousif MHM, et al. Cationic Polyamidoamine Dendrimers as Modulators of EGFR Signaling In Vitro and In Vivo. PloS one. 2015;10(7):e0132215. 10.1371/journal.pone. 0132215

27. Dolman ME, van Dorenmalen KM, Pieters EH, Sparidans RW, Lacombe M, Szokol B, et al. Dendrimer-based macromolecular conjugate for the kidney-directed delivery of a multitargeted sunitinib analogue. Macromolecular bioscience. 2012;12(1):93-103.

28. Nagavarma B, Yadav HK, Ayaz A, Vasudha L, Shivakumar H. DIFFERENT TECHNIQUES FOR PREPARATION OF POLYMERIC NANOPARTICLES-A REVIEW. Asian Journal of Pharmaceutical \& Clinical Research. 2012; 5(3):1623.

29. Kingsley J, Dou H, Morehead J, Rabinow B, Gendelman H, Destache C. Nanotechnology: A Focus on Nanoparticles as a Drug Delivery System. Journal of Neuroimmune Pharmacology. 2006;1(3):340-50. DOI: 10.1007/s11481-006-9032-4

30. Maeda H, Wu J, Sawa T, Matsumura Y, Hori K. Tumor vascular permeability and the EPR effect in macromolecular therapeutics: a review. J Control Release. 2000;65(1-2):271-84. DOI: S01683659(99)00248-5 [pii]

31. Vicent MJ, Duncan R. Polymer conjugates: nanosized medicines for treating cancer. Trends Biotechnol. 2006;24(1):39-47. 
32. Torchilin VP. Targeted pharmaceutical nanocarriers for cancer therapy and imaging. AAPS J. 2007;9(2):E128-47. DOI: 10.1208/aapsj0902015

33. Marslin G, Sheeba CJ, Kalaichelvan VK, Manavalan R, Reddy PN, Franklin G. Poly(D,L-lactic-coglycolic acid) nanoencapsulation reduces Erlotinibinduced subacute toxicity in rat. J Biomed Nanotechnol. 2009;5(5):464-71.

34. Barghi L, Aghanejad A, Valizadeh H, Barar J, Asgari D. Modified Synthesis of Erlotinib Hydrochloride. Advanced Pharmaceutical Bulletin. 2012;2(1):11922. DOI: $10.5681 / \mathrm{apb} .2012 .017$

35. Barghi L, Asgari D, Barar J, Nakhlband A, Valizadeh $\mathrm{H}$. Synthesis, characterization and in vitro antitumoral evaluation of Erlotinib-PCEC nanoparticles. Asian Pacific journal of cancer prevention : APJCP. 2014;15(23):10281-7.

36. Barghi L, Asgari D, Barar J, Valizadeh H. Synthesis of PCEC Copolymers with Controlled Molecular Weight Using Full Factorial Methodology. Advanced Pharmaceutical Bulletin. 2015;5(1):51-6. DOI: 10.5681/apb.2015.007

37. Jeong JH, Nguyen HK, Lee JE, Suh W. Therapeutic effect of apatinib-loaded nanoparticles on diabetesinduced retinal vascular leakage. International journal of nanomedicine. 2016;11:3101-9. DOI: 10.2147/ijn.s108452

38. Lee JE, Kim KL, Kim D, Yeo Y, Han H, Kim MG, et al. Apatinib-loaded nanoparticles suppress vascular endothelial growth factor-induced angiogenesis and experimental corneal neovascularization. International journal of nanomedicine. 2017;12:4813-22.

39. Hasandoost L, Akbarzadeh A, Attar H, Heydarinasab A. In vitro effect of imatinib mesylate loaded on polybutylcyanoacrylate nanoparticles on leukemia cell line K562. Artificial cells, nanomedicine, and biotechnology. 2017;45(3):665-9. DOI: 10.1080/21691401.2016.1175444

40. Zeinali Sehrig F, Majidi S, Nikzamir N, Nikzamir N, Nikzamir M, Akbarzadeh A. Magnetic nanoparticles as potential candidates for biomedical and biological applications. Artificial cells, nanomedicine, and biotechnology. 2016;44(3):918-27. DOI: 10.3109/21691401.2014.998832

41. Xu Y, Karmakar A, Heberlein WE, Mustafa T, Biris AR, Biris AS. Multifunctional magnetic nanoparticles for synergistic enhancement of cancer treatment by combinatorial radio frequency thermolysis and drug delivery. Adv Healthc Mater. 2012;1(4):493-501. DOI: 10.1002/adhm.201200079

42. Stapleton S, Milosevic M, Allen C, Zheng J, Dunne M, Yeung I, et al. A mathematical model of the enhanced permeability and retention effect for liposome transport in solid tumors. PloS one. 2013;8(12):e81157.

DOI:
43. Immordino ML, Dosio F, Cattel L. Stealth liposomes: review of the basic science, rationale, and clinical applications, existing and potential. International journal of nanomedicine. 2006;1(3):297-315.

44. Deshpande PP, Biswas S, Torchilin VP. Current trends in the use of liposomes for tumor targeting. Nanomedicine (London, England). 2013;8(9):10.2217/nnm.13.118. DOI: 10.2217/nnm.13.118

45. Hosokawa S, Tagawa T, Niki H, Hirakawa Y, Nohga K, Nagaike K. Efficacy of immunoliposomes on cancer models in a cell-surface-antigen-densitydependent manner. British Journal of Cancer. 2003;89(8):1545-51. DOI: 10.1038/sj.bjc.6601341

46. Haubner R, Gratias R, Diefenbach B, Goodman SL, Jonczyk A, Kessler H. Structural and Functional Aspects of RGD-Containing Cyclic Pentapeptides as Highly Potent and Selective Integrin $\alpha \mathrm{V} \beta 3$ Antagonists. Journal of the American Chemical Society. 1996;118(32):7461-72. DOI: $10.1021 / \mathrm{ja} 9603721$

47. Aumailley M, Gurrath M, Muller G, Calvete J, Timpl $\mathrm{R}$, Kessler H. Arg-Gly-Asp constrained within cyclic pentapeptides. Strong and selective inhibitors of cell adhesion to vitronectin and laminin fragment P1. FEBS letters. 1991;291(1):50-4.

48. Park JA, Lee YJ, Lee JW, Lee KC, An GI, Kim KM, et al. Cyclic RGD Peptides Incorporating Cycloalkanes: Synthesis and Evaluation as PET Radiotracers for Tumor Imaging. ACS medicinal chemistry letters. 2014;5(9):979-82. DOI: $10.1021 / \mathrm{ml} 500135 \mathrm{t}$

49. Zheng Y, Ji S, Czerwinski A, Valenzuela F, Pennington M, Liu S. FITC-conjugated cyclic RGD peptides as fluorescent probes for staining integrin alphavbeta3/alphavbeta5 in tumor tissues. Bioconjugate chemistry. 2014;25(11):1925-41. DOI: 10.1021/bc500452y

50. Song Z, Lin Y, Zhang X, Feng C, Lu Y, Gao Y, et al. Cyclic RGD peptide-modified liposomal drug delivery system for targeted oral apatinib administration: enhanced cellular uptake and improved therapeutic effects. International journal of nanomedicine. 2017;12:1941-58. DOI: $10.2147 / \mathrm{ijn} . \mathrm{s} 125573$

51. Xu H, He C, Liu Y, Jiang J, Ma T. Novel therapeutic modalities and drug delivery - erlotinib liposomes modified with galactosylated lipid: in vitro and in vivo investigations. Artificial cells, nanomedicine, and biotechnology. 2017; 28:1-6. DOI: 10.1080/21691401.2017.1396222

52. Naseri N, Valizadeh H, Zakeri-Milani P. Solid Lipid Nanoparticles and Nanostructured Lipid Carriers: Structure, Preparation and Application. Advanced Pharmaceutical Bulletin. 2015 5(3):305-13. DOI: 10.15171/apb.2015.043 
53. Liu C-H, Wu C-T. Optimization of nanostructured lipid carriers for lutein delivery. Colloids and Surfaces A: Physicochemical and Engineering Aspects. 2010;353(2):149-56.

54. Beloqui A, Solinís MÁ, Rodríguez-Gascón A, Almeida AJ, Préat V. Nanostructured lipid carriers: Promising drug delivery systems for future clinics. Nanomedicine: Nanotechnology, Biology and Medicine. 2016;12(1):143-61.

55. Fang CL, Al-Suwayeh SA, Fang JY. Nanostructured lipid carriers (NLCs) for drug delivery and targeting. Recent patents on nanotechnology. 2013;7(1):41-55.

56. Li Q, Cai T, Huang Y, Xia X, Cole SPC, Cai Y. A Review of the Structure, Preparation, and Application of NLCs, PNPs, and PLNs. Nanomaterials. 2017;7(6):122. DOI: 10.3390/nano7060122

57. Bakhtiary Z, Barar J, Aghanejad A, Saei AA, Nemati E, Ezzati Nazhad Dolatabadi J, et al. Microparticles containing erlotinib-loaded solid lipid nanoparticles for treatment of non-small cell lung cancer. Drug Dev Ind Pharm. 2017;43(8):1244-53. DOI: 10.1080/03639045.2017.1310223

58. Gupta B, Poudel BK, Tran TH, Pradhan R, Cho HJ, Jeong JH, et al. Modulation of Pharmacokinetic and Cytotoxicity Profile of Imatinib Base by Employing Optimized Nanostructured Lipid Carriers. Pharm Res. 2015;32(9):2912-27. DOI: 10.1007/s11095015-1673-7 [doi]

59. Kawabata Y, Wada K, Nakatani M, Yamada S, Onoue S. Formulation design for poorly watersoluble drugs based on biopharmaceutics classification system: basic approaches and practical applications. International journal of pharmaceutics. 2011;420(1):1-10.

DOI:

10.1016/j.ijpharm.2011.08.032

60. Wu CY, Benet LZ. Predicting drug disposition via application of BCS: transport/absorption/ elimination interplay and development of a biopharmaceutics drug disposition classification system. Pharm Res. 2005;22(1):11-23.

61. Blagden N, de Matas M, Gavan PT, York P. Crystal engineering of active pharmaceutical ingredients to improve solubility and dissolution rates. Adv Drug Deliv Rev. 2007;59(7):617-30. DOI: 10.1016/j.addr.2007.05.011

62. Xia D, Cui F, Piao H, Cun D, Piao H, Jiang Y, et al. Effect of crystal size on the in vitro dissolution and oral absorption of nitrendipine in rats. Pharm Res. 2010;27(9):1965-76. DOI: 10.1007/s11095-010$0200-0$

63. Devasari N, Dora CP, Singh C, Paidi SR, Kumar V, Sobhia ME, et al. Inclusion complex of erlotinib with sulfobutyl ether-beta-cyclodextrin: Preparation, characterization, in silico, in vitro and in vivo evaluation. Carbohydrate polymers. 2015;134:54756. DOI: 10.1016/j.carbpol.2015.08.012
64. Dora CP, Trotta F, Kushwah V, Devasari N, Singh C, Suresh S, et al. Potential of erlotinib cyclodextrin nanosponge complex to enhance solubility, dissolution rate, in vitro cytotoxicity and oral bioavailability. Carbohydrate polymers. 2016;137:339-49.

DOI: 10.1016/j.carbpol.2015.10.080

65. Malamatari M, Somavarapu S, Taylor KM, Buckton G. Solidification of nanosuspensions for the production of solid oral dosage forms and inhalable dry powders. Expert opinion on drug delivery. 2016;13(3):435-50. $10.1517 / 17425247.2016 .1142524$

66. Van Eerdenbrugh B, Van den Mooter G, Augustijns P. Top-down production of drug nanocrystals: nanosuspension stabilization, miniaturization and transformation into solid products. International journal of pharmaceutics. 2008;364(1):64-75. DOI: 10.1016/j.ijpharm.2008.07.023

67. Peltonen L, Valo H, Kolakovic R, Laaksonen T, Hirvonen J. Electrospraying, spray drying and related techniques for production and formulation of drug nanoparticles. Expert opinion on drug delivery. 2010;7(6):705-19.

DOI: $10.1517 / 17425241003716802$

68. Thakkar S, Sharma D, Misra M. Comparative evaluation of electrospraying and lyophilization techniques on solid state properties of Erlotinib nanocrystals: Assessment of In-vitro cytotoxicity. European journal of pharmaceutical sciences : official journal of the European Federation for Pharmaceutical Sciences. 2018;111:257-69. DOI: 10.1016/j.ejps.2017.10.008

69. Newman A, Knipp G, Zografi G. Assessing the performance of amorphous solid dispersions. Journal of pharmaceutical sciences. 2012;101(4):1355-77.

70. Einfal T, Planinsek O, Hrovat K. Methods of amorphization and investigation of the amorphous state. Acta pharmaceutica (Zagreb, Croatia). 2013;63(3):305-34. DOI: 10.2478/acph-2013-0026

71. Viel Q, Brandel C, Yohann C, eusébio E, Canotilho J, Dupray V, et al. Crystallization from the Amorphous State of a Pharmaceutical Compound: Impact of Chirality and Chemical Purity2016. DOI: 10.1021/acs.cgd.6b01566

72. Janssens S, Van den Mooter G. Physical chemistry of solid dispersions. Journal of Pharmacy and Pharmacology. 2009;61(12):1571-86.

73. Herbrink M, Schellens JHM, Beijnen JH, Nuijen B. Improving the solubility of nilotinib through novel spray-dried solid dispersions. International journal of pharmaceutics. 2017;529(1-2):294-302. DOI: 10.1016/j.ijpharm.2017.07.010

74. Shukla S, Skoumbourdis AP, Walsh MJ, Hartz AM, Fung $\mathrm{KL}, \mathrm{Wu} \mathrm{CP}$, et al. Synthesis and characterization of a BODIPY conjugate of the BCRABL kinase inhibitor Tasigna (nilotinib): evidence 
for transport of Tasigna and its fluorescent derivative by $\mathrm{ABC}$ drug transporters. Molecular pharmaceutics. 2011;8(4):1292-302. DOI: 10.1021/mp2001022

75. Bandyopadhyay S, Katare OP, Singh B. Optimized self nano-emulsifying systems of ezetimibe with enhanced bioavailability potential using long chain and medium chain triglycerides. Colloids and surfaces B, Biointerfaces. 2012;100:50-61. DOI: 10.1016/j.colsurfb.2012.05.019

76. Mohd AB, Sanka K, Bandi S, Diwan PV, Shastri N. Solid self-nanoemulsifying drug delivery system (SSNEDDS) for oral delivery of glimepiride: development and antidiabetic activity in albino rabbits. Drug Deliv. 2015;22(4):499-508. DOI: 10.3109/10717544.2013.879753

77. Sermkaew N, Ketjinda W, Boonme P, Phadoongsombut N, Wiwattanapatapee R. Liquid and solid self-microemulsifying drug delivery systems for improving the oral bioavailability of andrographolide from a crude extract of Andrographis paniculata. European journal of pharmaceutical sciences : official journal of the European Federation for Pharmaceutical Sciences. 2013;50(3-4):459-66.

DOI: 10.1016/j.ejps.2013.08.006

78. Seo YG, Kim DH, Ramasamy T, Kim JH, Marasini N, Oh YK, et al. Development of docetaxel-loaded solid self-nanoemulsifying drug delivery system (SNEDDS) for enhanced chemotherapeutic effect. International journal of pharmaceutics. 2013;452(12):412-20. DOI: 10.1016/j.ijpharm.2013.05.034

79. Truong DH, Tran TH, Ramasamy T, Choi JY, Lee $\mathrm{HH}$, Moon C, et al. Development of Solid SelfEmulsifying Formulation for Improving the Oral Bioavailability of Erlotinib. AAPS PharmSciTech. 2016;17(2):466-73. DOI: 10.1208/s12249-015-03705.

80. Scheffler M, Di Gion P, Doroshyenko O, Wolf J, Fuhr U. Clinical pharmacokinetics of tyrosine kinase inhibitors: focus on 4-anilinoquinazolines. Clin Pharmacokinet. 2011;50(6):371-403. DOI: 10.2165/11587020-000000000-00000

81. van Erp NP, Gelderblom H, Guchelaar HJ. Clinical pharmacokinetics of tyrosine kinase inhibitors. Cancer treatment reviews. 2009;35(8):692-706. DOI: 10.1016/j.ctrv.2009.08.004

82. Mura P. Analytical techniques for characterization of cyclodextrin complexes in aqueous solution: a review. J Pharm Biomed Anal. 2014;101:238-50. DOI: $10.1016 /$ j.jpba.2014.02.022

83. Radu CD, Parteni O, Ochiuz L. Applications of cyclodextrins in medical textiles - review. J Control Release. 2016;224:146-57. DOI: 10.1016/j.jconrel.2015.12.046

84. Trotta F, Zanetti M, Cavalli R. Cyclodextrin-based nanosponges as drug carriers. Beilstein Journal of
Organic Chemistry. 2012;8:2091-9. DOI: 10.3762/bjoc.8.235

85. Torne SJ, Ansari KA, Vavia PR, Trotta F, Cavalli R. Enhanced oral paclitaxel bioavailability after administration of paclitaxel-loaded nanosponges. Drug Deliv. 2010;17(6):419-25. DOI: 10.3109/10717541003777233

86. Wu M, Sirota M, Butte AJ, Chen B. Characteristics of drug combination therapy in oncology by analyzing clinical trial data on ClinicalTrials.gov. Pacific Symposium on Biocomputing Pacific Symposium on Biocomputing. 2015:68-79.

87. Kudo K, Ohashi K, Ichihara E, Minami D, Kubo H, Sato A, et al. Abstract 1368: The impact of bevacizumab on combination low-dose afatinib and cetuximab therapy in lung cancer cells harboring activated EGFR mutations. Cancer Research. 2015;75(15 Supplement):1368-. DOI: 10.1158/15387445.am2015-1368

88. Lee JY, Sun JM, Lim SH, Kim HS, Yoo KH, Jung $\mathrm{KS}$, et al. A Phase Ib/II Study of Afatinib in Combination with Nimotuzumab in Non-Small Cell Lung Cancer Patients with Acquired Resistance to Gefitinib or Erlotinib. Clinical cancer research : an official journal of the American Association for Cancer Research. 2016;22(9):2139-45. DOI: 10.1158/1078-0432.ccr-15-1653

89. Seto T, Kato T, Nishio M, Goto K, Atagi S, Hosomi $\mathrm{Y}$, et al. Erlotinib alone or with bevacizumab as firstline therapy in patients with advanced non-squamous non-small-cell lung cancer harbouring EGFR mutations (JO25567): an open-label, randomised, multicentre, phase 2 study. The Lancet Oncology. 2014;15(11):1236-44. DOI: $10.1016 / \mathrm{s} 1470-$ 2045(14)70381-x

90. Ichihara E, Hotta K, Nogami N, Kuyama S, Kishino $\mathrm{D}$, Fujii $\mathrm{M}$, et al. Phase II trial of gefitinib in combination with bevacizumab as first-line therapy for advanced non-small cell lung cancer with activating EGFR gene mutations: the Okayama Lung Cancer Study Group Trial 1001. Journal of thoracic oncology : official publication of the International Association for the Study of Lung Cancer. 2015;10(3):486-91. DOI: 10.1097/jto.0000000000000434

91. Kudo K, Ohashi K, Makimoto G, Higo H, Kato Y, Kayatani $\mathrm{H}$, et al. Triplet therapy with afatinib, cetuximab, and bevacizumab induces deep remission in lung cancer cells harboring EGFR T790M in vivo. Molecular oncology. 2017;11(6):670-81. DOI: 10.1002/1878-0261.12063

92. Satoh T, Xu RH, Chung HC, Sun GP, Doi T, Xu JM, et al. Lapatinib plus paclitaxel versus paclitaxel alone in the second-line treatment of HER2-amplified advanced gastric cancer in Asian populations: TyTAN--a randomized, phase III study. Journal of clinical oncology : official journal of the American 
Society of Clinical Oncology. 2014;32(19):2039-49. DOI: $10.1200 / j \mathrm{co} .2013 .53 .6136$

93. Wei Y, Xu S, Wang F, Zou A, Zhang S, Xiong Y, et al. A novel combined micellar system of lapatinib and Paclitaxel with enhanced antineoplastic effect against human epidermal growth factor receptor-2 positive breast tumor in vitro. J Pharm Sci. 2015;104(1):16577. DOI: $10.1002 /$ jps. 24234

94. Hu H, Lin Z, He B, Dai W, Wang X, Wang J, et al. A novel localized co-delivery system with lapatinib microparticles and paclitaxel nanoparticles in a peritumorally injectable in situ hydrogel. J Control Release. $\quad 2015 ; 220(\mathrm{Pt} \quad$ A):189-200. DOI: 10.1016/j.jconrel.2015.10.018

95. Ravar F, Saadat E, Kelishadi PD, Dorkoosh FA. Liposomal formulation for co-delivery of paclitaxel and lapatinib, preparation, characterization and optimization. Journal of Liposome Research. 2016;26(3):175-87.

DOI: 10.3109/08982104.2015.1070174

96. Chen Y, Cheng Y, Zhao P, Zhang S, Li M, He C, et al. Co-delivery of doxorubicin and imatinib by $\mathrm{pH}$ sensitive cleavable PEGylated nanoliposomes with folate-mediated targeting to overcome multidrug resistance. International journal of pharmaceutics. 2018;542(1-2):266-79.

DOI: 10.1016/j.ijpharm.2018.03.024
97. Setareh J, Jaleh V. Co-delivery of Curcumin and Imatinib by Nanostructured Lipid Carriers in the Treatment of Lymphoma. Peer-review multidisciplinary pharmacy scientific journal. 2018;1(1):11.

98. Srikar R, Suresh D, Zambre A, Taylor K, Chapman $\mathrm{S}$, Leevy $\mathrm{M}$, et al. Targeted nanoconjugate codelivering siRNA and tyrosine kinase inhibitor to KRAS mutant NSCLC dissociates GAB1-SHP2 post oncogene knockdown. Scientific Reports. [Article]. 2016;6:30245. DOI: 10.1038/srep30245

99. Chen G, Kronenberger P, Teugels E, Umelo IA, De Greve J. Effect of siRNAs targeting the EGFR T790M mutation in a non-small cell lung cancer cell line resistant to EGFR tyrosine kinase inhibitors and combination with various agents. Biochemical and biophysical research communications. 2013;431(3):623-9. DOI: 10.1016/j.bbrc.2012.12.070

100.Mu C-F, Xiong Y, Bai X, Sheng Y-J, Cui J. Codelivery of Ponatinib and SAR302503 by Active Bone-Targeted Polymeric Micelles for the Treatment of Therapy-Resistant Chronic Myeloid Leukemia. Molecular pharmaceutics. 2017;14(1):274-83. DOI: 10.1021/acs.molpharmaceut.6b00872.

101.Lam JK, Liang W, Chan HK. Pulmonary delivery of therapeutic siRNA. Adv Drug Deliv Rev. 2012;64(1):1-15. DOI: 10.1016/j.addr.2011.02.006 